\title{
In silico approach to develop structure and functional analysis of response receiver regulator protein of the strain pseaudomonas fulva $12 x$
}

\author{
Pipasha Biswas \\ Department of Biochemistry and Bio-technology University of Science and Technology Chittagong
}

\begin{abstract}
In total world population, most of the people depend on rice as a staple food because it gives proper amount of nutrition, which help to people in leading healthy life mainly in the developing countries of Asia. This valuable plant is attacked by various types of micro-organism like bacteria. Under the pseaudomonas species, pseaudomonas fulva $12-x$ is one of the strain, contain receiver domain include regulator protein, which ultimately help them to maintain signal transduction pathway.so the aim is to find out new target site in this hazardous bacteria to develop a potential medicine that help in saving our crops without using fertilizer because fertilizer causes various types of environmental problem. Very little amount of information is known about the structural biology of pseaudomonas fulva 12-x,so using homology modeling of bioinformatics approach the tertiary structure of response receiver regulator protein of pseaudomonas fulva 12-x has determined. The model building was done by swiss model workspace. Then the model was evaluated and validated using PROCHEK, Verify 3d,PROSA and ERRAT in these the verify $3 d$ value was 0.70 suggest surrounding profile is good an (PROSA) determined the disallowed region contain $0.0 \%$ and allowed region contain $93.5 \%$ and most favored region contain $6.5 \%$ amino acid, which implies perfect sterochemical quality of the model. Then physico-chemical characterization, secondary structure and functional site prediction were determined using Expasys protparam server, GOR4, SOPMA and Scan prosite tools. Finally, the active site was analyzed using CASTp server, which predicted target region and help in developing medicine for various rice diseases like bacterial PANICLE BLIGHT disease in further lab test.
\end{abstract}

\section{Introduction}

Bacterial panicle blight is a seed borne diseases of rice and gradually making a big problem in Arkansas since 1995 when it hugely destroyed Bengal and cypress cultivators' state wide. Rod shaped bacteria of soil cause hampers of these rice grain and stops crop production by up to $60 \%$.Various fertilization process has been suggested to do but no use give appropriate result [1].The bacterium Pseaudomonas fulva is a member of pseaudomonas pudina group, which is regarded as a soil bacterium group .pseudomonas fulva are the main bacterium of causing all kind of rice diseases, because they were collected mainly from rice grains [2][3]. In the cellular control process, phosphorylation of protein is a very important event [4][5] because it mediate most of the organism in signal transducing system like bacteria, microbial eukaryote \& higher plants [7][8] protein phosphorylation is a central to the function of two large protein familes,one is response regulator protein \& another is haloacid dehalogenases superfamily of hydrolase.[6]

Two component regulatory signaling system is the most common process in higher plants such as dicoid plant, but a slight knowledge has been gathered about the response receiver regulator protein of monocoid plant like rice. Cytokinin is a plant hormone and mediates in plant growth and development. It acts as signaling system like bacterial two component signaling system [9][10][11].

Generally using the regulatory system bacteria \& plant both adapt itself in any environmental condition [12]. Reasons behind the name of two component regulatory system are the presence of input \& output system.

Hisdine kinase which act as input system for receiving all kind of signal, which mediate bacteria to adapt in any type of environment feature like osmotic condition, $\mathrm{pH}$, temperature or to resist any complex hazardous ionic compound dissolved in that soil condition. This inputting system also sucks various macro and micro nutrient, so that remain balance in the concentrations. Another name of it is sensor kinase that holds some important characteristics like presence of transmembrane helices and continuous settlement of sensor system at the Nterminal input domain form in the cytoplasmic membrane layer of the protein.

When a signaling component binds with environmental stimulus, it evolves stimulation and this signal is passed from $\mathrm{N}$-terminal input domain to c-terminal output domain. In this middle time, signal which coming from input domain cause intramolecular structure alteration, that lead to the activation of cytoplasmic carrier domain [13][14][15][16]. This carrier activates nearest the receiver domain of response regulator protein. Response regulator is output system where phosphorylation related reaction occurs. Using a divalent cation both phosphorylation \& dephosphorylation reaction occur in receiver domain. So phosphorylation in the active site of 
this receiver domain, an altered form of stimulation from the expressed target gene is come out from regulatory system that control various expression according to its needs. [17]

In this study, we determined the $3 \mathrm{~d}$ structure of the response receiver regulator protein that is signaling protein for pseaudomonas fulva strain 12-x and identified the active site for potential medicine target using in silico approach.

\subsection{Computational Methods}

\section{Material and Method}

The computational process of $3 \mathrm{~d}$ model develops included template identification, alignment of template with the target, model build up and creation of the structure. The sequence of response regulator receiver protein of pseaudomonas fulva 12-x (Accession ID:-YP_004474011.1) was obtained from NCBI database.

\subsection{Template identification and sequence alignment}

Basic local alignment tool (Blast) [18] that was modified and maintained in Adam Godzik,s laboratory at the Burnham institute perform to identify the best template where it hits against the PDB(Brookhaven protein Databank)(19) database. In PSI-BLAST, a feature retrieved from nr protein database for proteins containing similarity to the unknown structure was used to find out PDB database.

\subsection{Model Build Up}

The model build up of response receiver regulator protein of pseaudomonas fulva $12-\mathrm{x}$ as a PDB file was done using CPH model 3.0 [20] server program which is homology modeling method related, then it was submitted to swiss model workspace server [21][22] to gain the 3D homology structure.

\subsection{Evolution and validation of model}

The Program PROCHEK [23] by ramachandan plot analysis is used to define the stereo chemical quality of the generated model and it was validated by verify 3D [24][25] and ERRAT programs [26]. To check the 3D structure of the generated protein model PROSA tool was used [27].

\subsection{Physical and chemical characterization}

Expasys protparam server is widely used in determining the physico-chemical characteristics of the generated protein model [32].

\subsection{Secondary structure and functional site determination}

Two self-optimized determination methods SOPMA [36] and GOR IV [35] Program were mediated to develop secondary structure of the protein. The functional site present in response receiver regulator protein of pseaudomonas fulva 12-x was calculated using Expasy's scan prosite tool [33].

\subsection{Active site prediction}

To identify the ligand binding capacity with the determined model, CASTp server [37] was used. The predicted active site in generated model will help in further work to study on docking site.

\subsection{Template choice with sequence alignment}

\section{Result}

The structure of the response receiver regulator protein of pseaudomonas fulva 12-x was performed based on the availability of the template sequence of the signaling protein from helicobacter pylori (PDB CODE:-3H1G) [9].

\subsection{3d Structure}

The 3D model of response receiver regulator protein of pseaudomonas fulva $12-x$ was generated by homology modeling on the template, which is collected from protein data bank [figure 1] 


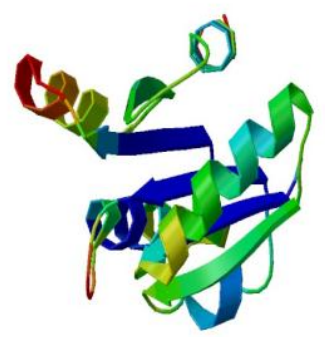

Fig 1: 3D structure of the response receiver regulator protein of Pseaudomonas fulva strain 12-X

\subsection{Evolution of model}

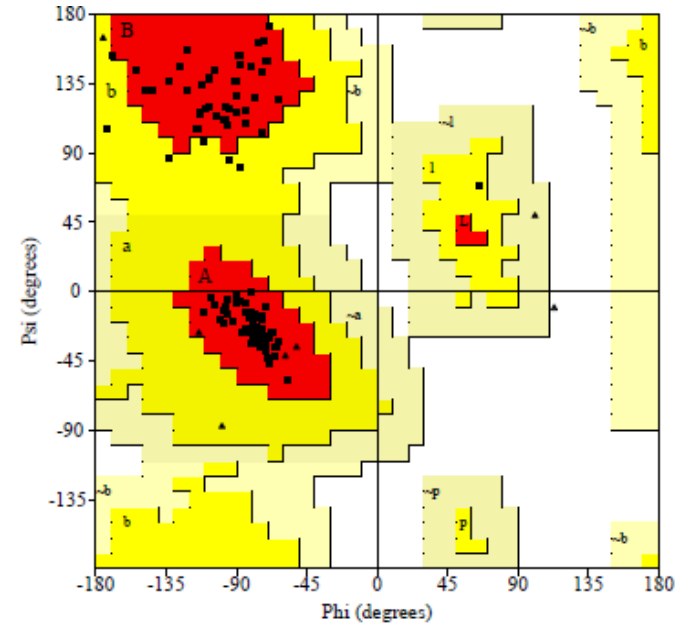

Figure 3: Ramachandan plot analysis of response receiver regulator protein of Table 1:

\begin{tabular}{|l|rr|}
\hline & & \\
Residues in most favoured regions [A,B,L] & 100 & $93.5 \%$ \\
Residues in additional allowed regions [a,b,l,p] & 7 & $6.5 \%$ \\
Residues in generously allowed regions [ $\sim \mathrm{a}, \sim \mathrm{b}, \sim \mathrm{L}, \sim \mathrm{p}]$ & 0 & $0.0 \%$ \\
Residues in disallowed regions & 0 & $0.0 \%$ \\
& $\mathbf{1 0 7}$ & $\mathbf{1 0 0 . 0 \%}$ \\
& 2 & \\
Number of non-glycine and non-proline residues & 7 & \\
Number of end-residues (excl. Gly and Pro) & -1 & \\
Number of glycine residues (shown as triangles) & $\mathbf{1 2 0}$ \\
Number of proline residues & \\
Total number of residues & \\
\hline
\end{tabular}

Pseaudomonas fulva 12-x was calculated using PROCHEK

\subsection{Verification of 3D model}

The profile score above zero in the verify $3 \mathrm{D}$ graph suggest the approvable environment profile of the model [figure 4]. ERRAT [26] analyzes the statistics of non-bonded interactions between different atom types and plots the value of the error function versus position of a residue [figure 5]. The results PROSA program [27] used for the display of scores and energy plots that highlight potential problems spotted in the modeled protein structure are shown in [figure 6].

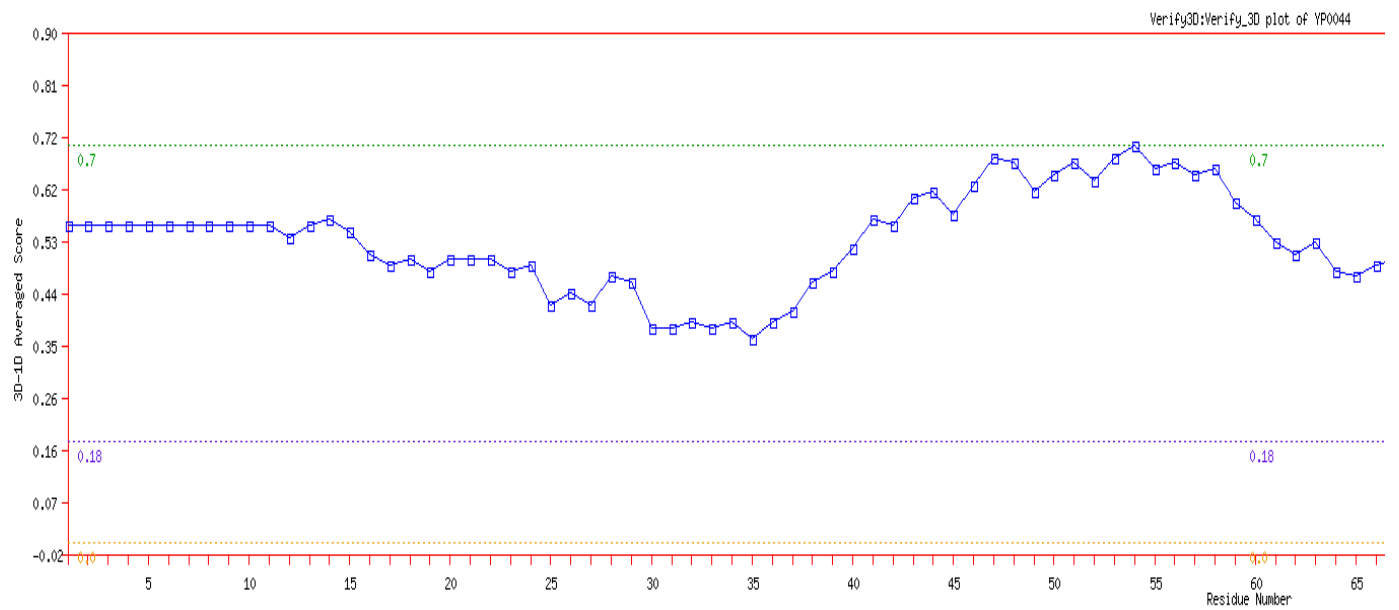

Figure 4: verify 3D GRAPH of response receiver regulator protein of Pseaudomonas fulva 12-x obtained using modeling tool. 


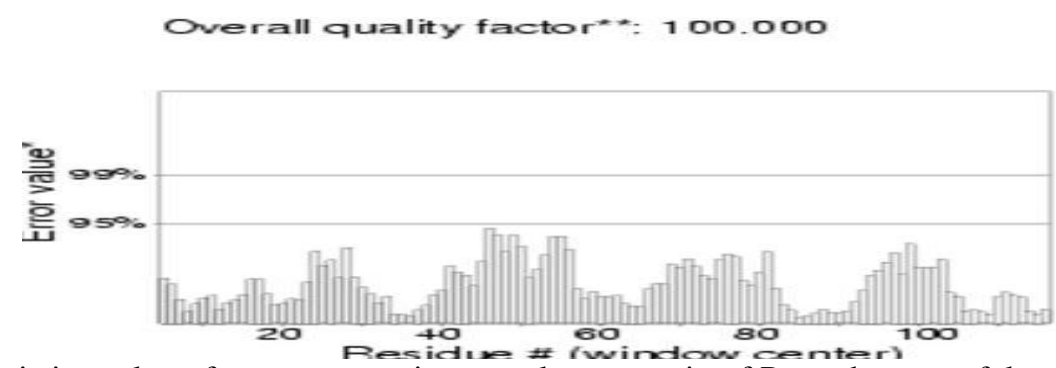

Figure 5: plot statistics value of response receiver regulator protein of Pseaudomonas fulva 12-x obtained using (ERRAT) modeling tool. Expressed as the percentage of the protein for which the calculate error value falls below the 95\% rejection limit. Good high resolution structures generally produce values around $95 \%$ or higher. For lower resolution (2.5 to $3 \mathrm{~A}$ ) the average overall quality factor is around $91 \%$.

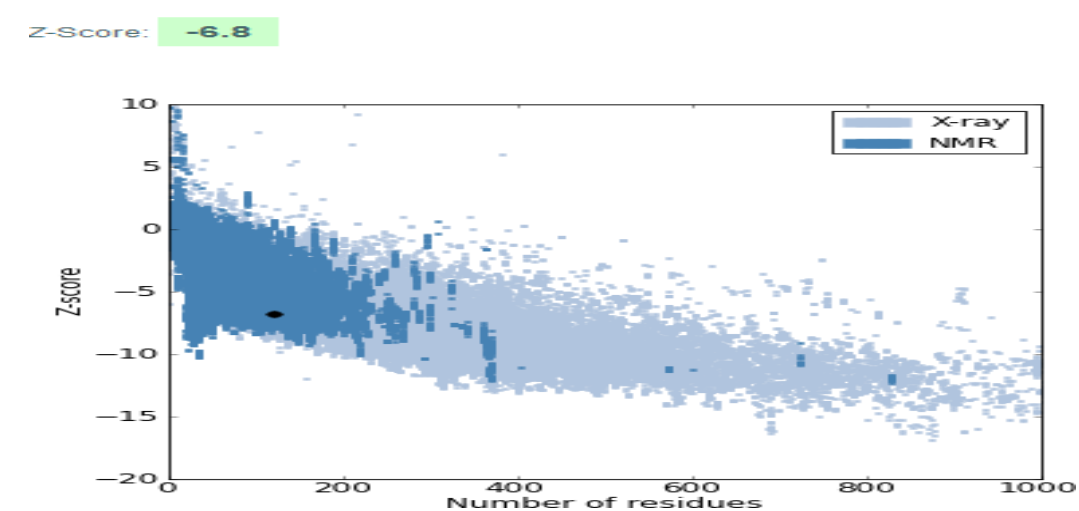

Figure 6: Z score for the response receiver regulator protein of Pseaudomonas fulva 12-x obtained from modeling tool PROSA

\subsection{Physical and chemical characterization:}

The pyshico-chemical characteristics is used to know number of amino acids, molecular weights, total number of negatively and positively charged residues, Theoretical $\mathrm{pI}$ (isoelectric point), Extinction coefficient (EI) [28], Instability index(II) [29][30], grand average of hydropathicity (GRAVY) and aliphatic index (AI) [31],.These features are determined using Expasys protparam server, which are presented in table 2

\begin{tabular}{|l|c|}
\hline Number of amino acids & 13882.1 \\
\hline Molecular weight & 5.45 \\
\hline Theoretical pI & 17 \\
\hline Total number of negatively charged residues(Asp+Glu) & 16 \\
\hline Total number of positively charged residues(Arg+Lys) & 6990 \\
\hline Extinction co efficients & 26.93 \\
\hline Instability index & 103.79 \\
\hline Aliphatic index & -0.001 \\
\hline Grand average of hydropathicity(GRAVY) & \\
\hline
\end{tabular}

Table2: Physico-chemical features value of response receiver regulator protein of pseudomonas fulva 12-x obtained using modeling tool.

\subsection{Secondary structure and functional site prediction}

The secondary structure analysis is used to know the composition of alpha helix strand and beta coil in the modeled protein. Secondary structural characteristics are obtained using SOPMA and GOR IV is presented in table 3 and 4. Using fault parameter of SOPMA in which window width 


\begin{tabular}{|l|l|}
\hline Secondary structure & $(\%)$ \\
\hline Alpha helix & 46.58 \\
310 helix & 0.00 \\
Pi helix & 0.00 \\
Beta bridge & 0.00 \\
Extended strand & 17.74 \\
Beta turn & 10.48 \\
Bend region & 0.00 \\
Random coil & 25.00 \\
Ambiguous states & 0.00 \\
Other states & 0.00 \\
\end{tabular}

TABLE 3: Computed secondary structural elements of response receiver regulator protein of pseaudomonas fulva 12 -X by SOPMA.

is 17 , similarity threshold is 8 and number of states is 4 and GOR IV, the secondary structure is determined. The output of using Scanprosite tool that is recorded in terms of the length of amino residues of modeled protein with specific profile and pattern is represented in table 3.

\begin{tabular}{|l|l|}
\hline Secondary structure & $(\%)$ \\
\hline Alpha helix & 47.58 \\
${ }^{10}$ helix & 0.00 \\
Pi helix & 0.00 \\
Beta bridge & 0.00 \\
Extended strand & 13.71 \\
Beta turn & 0.00 \\
Bend region & 0.00 \\
Random coil & 38.71 \\
Ambiguous states & 0.00 \\
Other states & 0.00 \\
& \\
\hline
\end{tabular}

Table 4: Computed secondary structure of response receiver regulator protein of pseudomonas fulva $12-\mathrm{x}$ by GOR IV

\begin{tabular}{|l|c|}
\hline \multicolumn{1}{|c|}{ Length of amino residues of modeled protein with specific profiles \& pattern } & $\begin{array}{c}\text { Functional region } \\
\text { position }\end{array}$ \\
\hline MKILIVDDFSTMRRIIKNLLRDLGFTNTAEADDGVTALPMLQSGNFDFLVTDWNMPGMTGIDLLRA & $2-119$ amino acid \\
VRADERLKQLPVLMVTAEAKRDQIIEAAQAGVNGYVKPFTAQVLKEKIEKIFERVNG & \\
\hline
\end{tabular}

Table 5: Functional site present in response receiver regulator protein of Pseaudomonas fulva 12-x obtained using Scan Prosite tool in Expasys

\subsection{Active site prediction}

CASTp server is used for active site determination of response receiver regulator protein of Pseaudomonas Fulva 12-x (figure 6), then also reported the best active site area and the position of amino acid and other amino acid involved in it [figure 7]

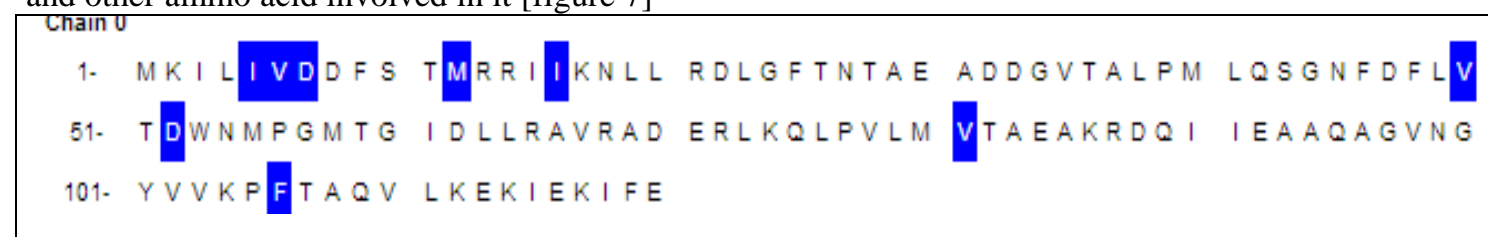

Figure 6: Active site prediction by CASTp server, where Green color shows the active site position from 5 to 106 with the Beta sheet in between them. 


\begin{tabular}{|c|c|c|c|}
\hline & ID & Area & Vol \\
\hline$\square$ & 8 & 98.7 & 85 \\
\hline 目 & 7 & 126.6 & 82.4 \\
\hline$\square$ & 8 & 57.5 & 45.6 \\
\hline$\square$ & 5 & 27.7 & 22.4 \\
\hline$\square$ & 4 & 16.5 & 10.9 \\
\hline$\square$ & 3 & 26 & 12.3 \\
\hline$\square$ & 2 & 9.1 & 5.7 \\
\hline$\square$ & 1 & 24.7 & 11.5 \\
\hline
\end{tabular}

Figure 7: The table shows the area and the volume

For different active sites in response receiver regulator protein Of Pseaudomonas fulva 12-x and the best active site area exist in an area of 126.6 and a volume of 82.4 .

\section{Discussion}

In the field of bioinformatics, homology modeling algorithm is regarded as an interesting site for any biological experiment and in other silico work planning. Homology modeling is the appropriate method to estimate structure related protein molecule and functional information. For 3D structure generation, need to homology search which is done from PDB to identify template structure then alignment of target sequence and template structure from nr protein Database searched by BLASTp.Various protein model designing software are developing day by day, with raising number of known protein structure. In this study, Model build up is done using different program which suggest that the proteins contains alpha helix, beta strand and loop. The program $\mathrm{CPH}$ model 3.o server was used to save query sequence as PDB file, then submit to another web based software ,name swiss - prot workspace that reduce the problem of downloading and installising wide range of program packages and databases [40]. PROCHEK program check the Stereo chemical quality and perfection of the developed models that shows amino acid percentage in the favorable region was $93.5 \%$ and in the disallowed region was $0.0 \%$. In total $100 \%$ of the amino acid residues present in favored and allowed region that was illustrated in the ramachandan plot (figure2) with statics(table 1). Verify 3D server show the compatibility of an atomic model (3D) with its own amino acid sequence(1D) by assigned a structural class depend on its position and environmental profile (Alpha sheet, beta loop, polar, non-polar etc. ) and determine the better qualityful structure.

Another validation program ERRAT shows the overall quality factor for the modeled protein is $100 \%$ which indicate good resolution structure (fig 3).

The verify 3D graph shown the value 0.70 (fig 4), where 3D-1D score greater then 0.2 suggest the environmental condition for side chain are acceptable. Modeled protein was also examined by X-ray-NMR studies, which shown the point of the structure within a range. Energy plot for modeled protein implies using "PROSA" tool [27], where Z score is -6.8 and represent native conformation quality is good (fig 5).

The Physico-chemical characteristics of the modeled protein is calculated using Expasy's protparam tool(Table 2) [39], where Isoelectric point value less then 7 suggest the protein as acidic in nature and suitable for developing buffer system to purify using isoelectric focusing method. The protein also contain almost nearest number of positively and negatively charged residues. On the other side, EXPASY'S protparam computes the extinction coefficient for this protein at $280 \mathrm{~nm}$ wavelength, because this wavelength helps protein to absorb strongly, while other substances can't absorb like that in the protein solution. Extinction coefficient value is $6990 \mathrm{M}-1 \mathrm{~cm}-1$ at $280 \mathrm{~nm}$ measured in water which also suggests the protein can't be analyzed using X-ray and NMR spectral method but not using UV spectral methods. Another parameter is instability index determine the stability of this modeled protein in a test tube. Molecular weight value of this protein help to calculate an instability index.Naturally, if the instability index value less then 40 is indicated as stable, a value above 40 indicate as unstable. This instability index value for this protein is 26.93 , the result suggest the response receiver regulator as stable protein. On the basis of Aliphatic index Expasy's protparam, indicate highest value of response receiver regulator protein that predicates the protein remain stable for a large range of temperature. Aliphatic index for the response receiver regulator receiver of pseudomonas fulva 12-x is 103.79.The Grand average hydropathy (GRAVY) value for a protein is calculated as the sum of hydropathy values of all the amino acids divided by the number of residues in the sequences. This parameter gives the value -0.01 that suggest the possibility of better interaction of the modeled protein with water at lower range value [39]. The secondary structure is determined using GOR IV and sopma shown in table 3 and 4 from which it is clear that random coil,alpha helix and extended strand, all are present in predominant amount that is the best site of a good structure. The output of scan prosite tool [34]was calculated in association of the length of amino residues of 
protein with specific profile and pattern that guidance in molecular function determination. Important information can be gathered, if the binding site of protein is determined, which help to suggest in experimental technique that predict $46.58 \%$ alpha helix, $25 \%$ random coil, $17.74 \%$ extended strand according to SOPMA and $47.58 \%$ alpha helix, $38.71 \%$ random coil, $13.71 \%$ extended strand according to GOR IV tools, presence in the complex modeled protein structure.[38]To calculate pockets and voids on 3D structure of the modeled protein and indicate the active site use CASTp program that is online tool. The program predicts best active site has an area of 126.6 and volume 82.4(figure 7). The best active site position of the modeled protein as well as the amino acid in the in the active site shown in blue color starting from amino acid 5 to some interaction with amino acid 106.The main coverage of amino acid present in building cavities between 5-7.

\section{Conclusion}

The knowledge of homology modeling \& functional region searching tool act as a fundamental way that will give various possible application of modeled protein of pseudomonas fulva 12-x help of enzyme inhibition assay in further experiment. In this study, the native conformation create purpose of modeled protein, give the answer about ligand binding affinity and show effort in designing mutagenesis experiment. All the information collect from above studies will assist to explore the search on perfect inhibitor of response receiver regulator protein from pseudomonas fulva 12-x,that can be used in future plant medicine development project.

\section{Reference:-}

[1]. Mary Hightower.Resistence against bacterial panicle blight in rice. Delta farma press.2011.

[2]. Renault D, Deniel F, Benizri F, Sohier D, Barbier G,Rey P.Characterization of Bacillus and pseudomonas strains with suppressive traits isolated from tomato hydroponic-slow filtration unit. Can J Microbial.2007;53:784-97.

[3]. Uchino M, Shida O,Uchimura T, Komagata k.Recharacterization of Pseudomonas fulva lizuka and Komagata 1963, and proposals Pseudomonas parafulva sp. nov. and Pseudomonas cremoricolorata sp.nov.J Gen Appl Microbial. 2001;47:247-261.

[4]. Post RL, Kume S.Evidence for an aspartyl phosphate residue at the active site of sodium and potassium ion transport adenosine triphosphate.J Biol Chem. 1973; 248:6993-7000.

[5]. V Weiss,B Magasanik.Phosphorylation of nitrogen regulator I (NRI) of Escherichia coli.Proc Natl Acad Sci U S A. 1988;85:89198923.

[6]. Hoch JA, Sihavy TJ. Two component signal transduction (Am.Soc.Microbiol.,Washington. DC) 1995

[7]. Djordjevic s and A.M Stock. Structural analysis of bacterial chemotaxix proteins: components of a dynamic signaling system.J.struct Biol. 1998;124:189-200.

[8]. Falke JJ,Bass RB,Butler SL,Chervitz SA,Danielson MA.The Two-component signaling pathway of bacterial chemotaxix :a molecular view of signal transduction by receptors,kinases and adaptation enzymes.Annu Rev cell Dev Biol. 1997;13:457-512.

[9]. Mukesh jain, Akhilesh k tyagi, Jitendra $\mathrm{p}$ khurana..Molecular characterization and differential expression of Cytokinin-responsive type-A response regulators in rice (Oryza sativa).BMC plant Biology. 2006;6:1

[10]. Mok DW, Mok MC.Cytokinin Metabolism and Action.Annu Rev plant physiol plant Biol. 2001;52:89-118

[11]. Davies pj.Plant hormone, Biosynthesis, signal transduction,Action.The Netherlands:Kluwer Academic press;2004.

[12]. West AH,Stock A.M.Histidine kinases and response regulator proteins in two component signaling system .2001.Trends Biochem sci;26:369-376.

[13]. Hoch, J.A., and T.J. Silhavy(ed.).Two component signal transduction.ASM press,washington,D.C.1995.

[14]. Inouye. M and R .Dutta (ed.).Hisdine kinases in signal transduction. Academic press, San Diego,Calif.2003.

[15]. Wolanin, P.M., P.A.. Thomason and J.B. Stock.Histidine protein kinases: key signal transducers outside the animal kingdom. Genome Biol .2002;REVIEWS301.

[16]. Schultz, J ., F.Milpetz, P.Bork and C.P.Ponting.SMART,a simple modular architecture research tool: identification of signaling domains.Proc.Natal.Acad.Sci.USA .1998:95:5857-5864.

[17]. Bourret RB.Receiver domain structure and function in response regulator protein.Curr Opin Microbiol. 2010;13:142-149

[18]. Altschul SF, Gish W,Miller W, Myers EW,Lipman DJ.Basic local alignment search tool .J Mol Biol .1990;215:403-10[pubmed]

[19]. Berman HM,Westbrook j, Feng Z,Gilliland G, Bhat TN,Weissig H,et al.The Protein Data Bank. Nucleic acids Res. 2000;28:23542.[pub med]

[20]. Nielsen M, Lundergaard C, Lund o,Petersen TN.CPH models-3.0.Remote homology modeling using structure guided sequence profiles. Nucleic Acids Res. 2010;38(Web server issue) w576-81.

[21]. Bordoli L,Kiefer F,Arnold K,Benkert p, Battey j, Schwede T.protein structure homology modelng using SWISS-MODEL workspace.Nat protoc .2009;4:1-13

[22]. Arnod K, Bordoli L, Kopp J, Schwede T.The SWISS-MODEL Workspace:A web -based environment for protein structure homology modelling.Bioinformatics . 2006;22:195-201

[23]. Laskowaski RA, Rullmannn JA, MacArthur MW, Kaptein R, Thornton JM.AQUA and PROCHEK-NMR programs for checking the quality of protein structures solved by NMR.J Biomol NMR. 1996;8:477-86.

[24]. Bowie JU, Lüthy R,Eisenberg D.A method to identify protein sequence that fold into a known three-dimensional structure.Science .1991;253:164-70.

[25]. Lüthy R,Bowic JU,Eisenbery D.Assessment of protein models with three-dimensional profiles.Nature .1992;356:83-5

[26]. Colovos VC and Yeast TO. Verification of protein structures: pattern of nonbonded atomic interactions. Protein sci. 1993;2:1511[pubmed]

[27]. Sippl MJ.Recognition of errors in three-dimensional structures of proteins.Proteins.1993;17:355[pubmed]

[28]. Gill SC \& von Hippel PH.Calculation of protein extinction coefficients from amino acid sequence data.Anal Biochem. 1989;182:319.

[29]. Guruprasad K et al.Correlation between stability of a protein and it's dipeptide composition: a novel approach for predicting in-vivo stability of a protein from it's primary sequence. Protein Eng. 1990;4:155.

[30]. Ikai A.Thermostability and aliphatic index of globular proteins.J Biochem. 1980;88:1895.

[31]. Kyte J \&Doolittle RF.A simple method for displaying the hydropathic character of a protein.J Mol Biol. 1982;157:105. 
[32]. Wilkins MR et al.Protein identification and analysis tools in the Expasys server. Methods Mol Biol .1999;112:531.

[33]. Gattiker A,Gasteiger E and Bairoch A.Scan Prosite:a reference implementation of a PROSITE scanning tool.Appl Bioinformatics. 2002;1;107-108.

[34]. ED castro, et al.ScanProsite:detection of PROSITE signature matches and ProRule-associated functional and structural residues in proteins. Nucleic Acids Res. 2006;34:w362-w365.

[35]. Garnier J,Gibrat J-F,Robson B.GOR secondary structure prediction method version IV.Methods in Enzymology. 1996;266:540-553.

[36]. Geourjon C,Deleage G.SOPMA:significant improvements in protein secondary structure prediction by consensus prediction from multiple alignments comput.Appl Biosci. 1995;11:681-4.

[37]. Dundas J,Ouyang Z,Tseng J,Binkowski A,Turpoz Y and Liang J.CASTp:Computed atlas of surface topography of proteins with structure and topographical mapping of functionally annotated residues.Nucleic Acids Res. 2006;34(web server issue):w116-8.

[38]. Neelmathi E,Vasumathi E, Bagyalakshmi S,Kannam R.Insilico prediction of structure and functional aspects of a hypothetical protein of Neurospora crassa . J Cell Tissue Re.2009;9:1989-94.

[39]. Suseep Roy et al.Structure prediction and functional characterization of secondary metabolite proteins of Ocimum.Bioinformation.2011;6:315-319.

[40]. M ullah, J Hira et al.A bioinformatics approach for homology modeling and binding site idetification of triosephosphate isomerase from Plasmodium falciparum 3D7.J Young Pharm.2012;4:261-266. 